\title{
Article \\ Detection of the First Epoxyalcohol Synthase/Allene Oxide Synthase (CYP74 Clan) in the Lancelet (Branchiostoma belcheri, Chordata)
}

\author{
Yana Y. Toporkova *, Elena O. Smirnova, Natalia V. Lantsova, Lucia S. Mukhtarova and Alexander N. Grechkin * \\ Kazan Institute of Biochemistry and Biophysics, FRC Kazan Scientific Center of RAS, P.O. Box 30, \\ 420111 Kazan, Russia; yelena.smirnova@aiesec.net (E.O.S.); natamed2@yandex.ru (N.V.L.); \\ lucia74@yandex.ru (L.S.M.) \\ * Correspondence: toporkova@kibb.knc.ru (Y.Y.T.); grechkin@kibb.knc.ru (A.N.G.)
}

check for updates

Citation: Toporkova, Y.Y.; Smirnova, E.O.; Lantsova, N.V.; Mukhtarova,

L.S.; Grechkin, A.N. Detection of the First Epoxyalcohol Synthase/Allene Oxide Synthase (CYP74 Clan) in the Lancelet (Branchiostoma belcheri, Chordata). Int. J. Mol. Sci. 2021, 22, 4737. https://doi.org/10.3390/ ijms22094737

Academic Editor: Christophe Morisseau

Received: 9 March 2021

Accepted: 27 April 2021

Published: 29 April 2021

Publisher's Note: MDPI stays neutral with regard to jurisdictional claims in published maps and institutional affiliations.

Copyright: (C) 2021 by the authors Licensee MDPI, Basel, Switzerland. This article is an open access article distributed under the terms and conditions of the Creative Commons Attribution (CC BY) license (https:/ / creativecommons.org/licenses/by/ $4.0 /)$.
Abstract: The CYP74 clan cytochromes (P450) are key enzymes of oxidative metabolism of polyunsaturated fatty acids in plants, some Proteobacteria, brown and green algae, and Metazoa. The CYP74 enzymes, including the allene oxide synthases (AOSs), hydroperoxide lyases, divinyl ether synthases, and epoxyalcohol synthases (EASs) transform the fatty acid hydroperoxides to bioactive oxylipins. A novel CYP74 clan enzyme CYP440A18 of the Asian (Belcher's) lancelet (Branchiostoma belcheri, Chordata) was biochemically characterized in the present work. The recombinant CYP440A18 enzyme was active towards all substrates used: linoleate and $\alpha$-linolenate 9- and 13hydroperoxides, as well as with eicosatetraenoate and eicosapentaenoate 15 -hydroperoxides. The enzyme specifically converted $\alpha$-linolenate 13-hydroperoxide (13-HPOT) to the oxiranyl carbinol (9Z,11R,12R,13S,15Z)-11-hydroxy-12,13-epoxy-9,15-octadecadienoic acid (EAS product), $\alpha$-ketol, 12 oxo-13-hydroxy-9,15-octadecadienoic acid (AOS product), and cis-12-oxo-10,15-phytodienoic acid (AOS product) at a ratio of around 35:5:1. Other hydroperoxides were converted by this enzyme to the analogous products. In contrast to other substrates, the 13-HPOT and 15-HPEPE yielded higher proportions of $\alpha$-ketols, as well as the small amounts of cyclopentenones, cis-12-oxo-10,15-phytodienoic acid and its higher homologue, dihomo-cis-12-oxo-3,6,10,15-phytotetraenoic acid, respectively. Thus, the CYP440A18 enzyme exhibited dual EAS/AOS activity. The obtained results allowed us to ascribe a name "B. belcheri EAS/AOS" (BbEAS/AOS) to this enzyme. BbEAS/AOS is a first CYP74 clan enzyme of Chordata species possessing AOS activity.

Keywords: cytochrome P450; CYP74; epoxyalcohol synthase; allene oxide synthase; Branchiostoma belcheri

\section{Introduction}

Lancelets or amphioxi are the only living cephalochordates [1]. These organisms, as well as the urochordates (sea squirts) and vertebrates (including the jawless lamprey and hagfish), belong to the Chordata phylum [2-5]. Despite the separate evolution of cephalochordate and vertebrates from a common ancestor (which existed more than 520 million years ago), their morphology maximally retained characteristics of vertebrate ancestor Haikouella lanceolata [6,7]. Lancelets are considered to be intermediate between vertebrates and invertebrates. Thereby, these organisms are widely used as a model object to study the evolution of invertebrates and the origin of vertebrates [7].

Oxylipins, the products of oxidative metabolism of polyunsaturated fatty acids, maintain homeostasis at the cellular and organismic levels in various living organisms [8]. The oxylipin biosynthesis via the lipoxygenase pathway occurs both in plants and Metazoa. Primary products of lipoxygenases, fatty acid hydroperoxides undergo further conversions, many of which are mediated by enzymes of P450 superfamily [9,10], the CYP74 clan proteins, and some other nonclassical P450s [11]. The largest diversity of CYP74s, the CYP74 
family members, occur in higher plants [12-14]. The recent detection of CYP74s in Metazoa, Proteobacteria [15], as well as the green [16] and brown [17] algae extended the diversity of CYP74s from family to the clan. There are several distinct kinds of CYP74 enzymes, including two dehydrases, namely, allene oxide synthase (AOS) [18] and divinyl ether synthase (DES) [19], and two isomerases, namely, hydroperoxide lyase (HPL, synonym hemiacetal synthase) [20-22] and epoxyalcohol synthase [15,17,23-25]. Moreover, some CYP74 enzymes possess dual HPL/EAS or trial HPL/EAS/AOS activities [26-29].

Only a few Metazoan proteins of the CYP74 clan have been described until now. These are the ApAOS of the stony coral Acropora palmata [15], BfEAS (CYP440A1) of the lancelet Branchiostoma floridae [15], and NvEAS (CYP443D1) [23] and NvHPL/EAS (CYP443C1) [26] of the starlet sea anemone Nematostella vectensis. At the same time, the NCBI database contains numerous annotated but uncharacterized metazoan CYP74 clan members. Characterization of novel CYP74 clan member from lancelet species B. belcheri is reported in the present work. The protein exhibiting the mixed EAS/AOS activity is a first CYP74 clan enzyme of Chordata species possessing the AOS catalysis.

\section{Results}

\subsection{Bioinformatics' Analysis of the CYP440A18 Enzyme}

The search for the putative genes of CYP74 clan in B. belcheri genome has been performed using TBLASTN and BLASTP tools at the NCBI database using BfEAS (CYP440A1; ACD88492.1) as query. The search revealed the target protein (458 aa; XP019641998.1) possessing $71 \%$ identity at $76 \%$ query coverage to BfEAS. Among green plants, the target protein possesses the highest identity to allene oxide synthases PpAOS2 (CYP74A8) of Physcomitrella patens (XP024372097.1) and LeAOS1 (CYP74A1) of Solanum lycopersicum (CAB88032.1): $26.95 \%$ and $26.86 \%$ identity at $83 \%$ and $75 \%$ sequence coverage, respectively. The name CYP440A18 has been assigned to this new sequence (Dr. David R. Nelson, personal communication).

Alignment of the CYP440A18 enzyme with other CYP74s revealed some features of primary structure typical for CYP74s such as the I-helix groove region (earlier "hydroperoxidebinding domain" [27], SRS-4), ERR-triad, PPV-domain, nine-amino acid insertion at the heme-binding domain, and cysteinyl heme ligand (Figure 1).

The catalytically essential I-helix groove region has the V-M-F-N-A-V sequence. This region contains the conserved $\mathrm{N}$ residue (N223 in the investigated enzyme) involved in the initial stage of CYP74 catalysis, i.e., the homolytic cleavage of the $\mathrm{O}-\mathrm{O}$ bond of fatty acid hydroperoxides [15]. Phylogenetic analyses using Clustal Omega and MEGA7 (the minimum evolution and the neighbor-joining methods) confirmed that the CYP440A18 enzyme belongs to the CYP74 clan. The epoxyalcohol synthase BfEAS (CYP440A1, GenBank: ACD42778.1) of lancelet B. floridae is the most similar to the CYP440A18 enzyme (bootstrap support is 100) (Figure 2).

Thus, the structural and phylogenetic data confirmed that the CYP440A18 enzyme belongs to the CYP74 clan.

Alignment of open reading frame encoding the CYP440A18 enzyme with the genomic sequence mapped a gene of $5154 \mathrm{np}$ length in a locus LOC109483426 (161,658-166,811, complement) and identified its structure. The coding sequence was interrupted into 5 exons by four introns. The target coding sequence adapted for expression in E. coli cells was custom synthesized by the Evrogen Company (Russia) and cloned into the vector pET-23a to yield the target recombinant protein with polyhistidine tag at C-terminus. His-tagged recombinant protein was obtained in BL21(DE3)pLysS strain cells (Novagen, USA) and purified by metal affinity chromatography. The enzymatic activity was controlled using the ultraviolet spectroscopy by the decrease of fatty acid hydroperoxide absorbance at $234 \mathrm{~nm}$. 


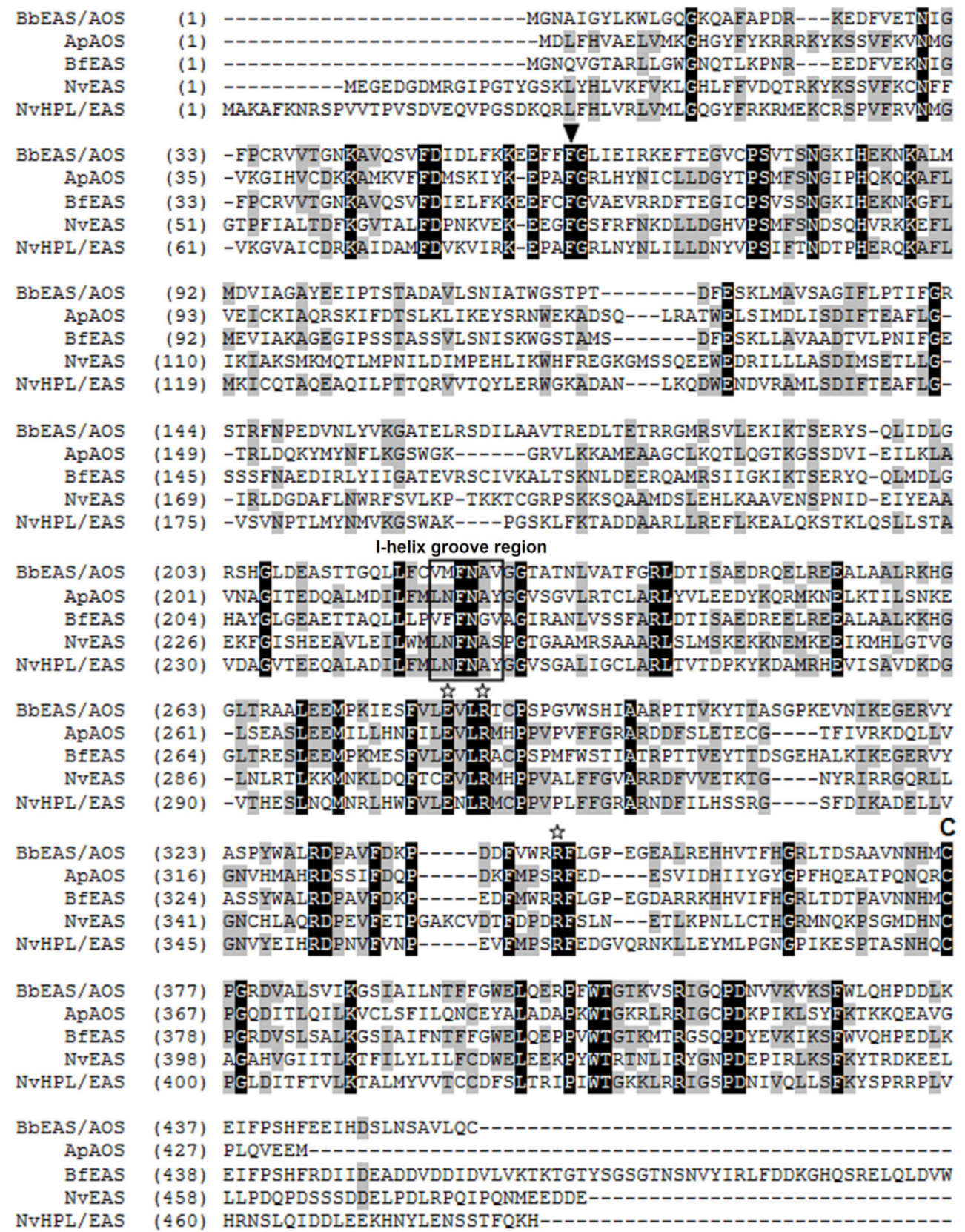

Figure 1. The multiple alignment of the CYP440A18 sequence with sequences of metazoan CYP74 clan members characterized earlier: Ap, Acropora palmata (coral); ApAOS, ACD42778.1; Bf, Branchiostoma floridae; BfEAS, ACD88492.1; Nv, Nematostella vectensis; NvEAS, XP_001636360.1; NvHPL/EAS, QJI54761.1. Conservative structures are marked as follows: the I-helix groove region is signed, while the F/L toggle, the ERR-triad, and the cysteinyl ligand are marked by triangle, stars, and $\mathrm{C}$, respectively. 


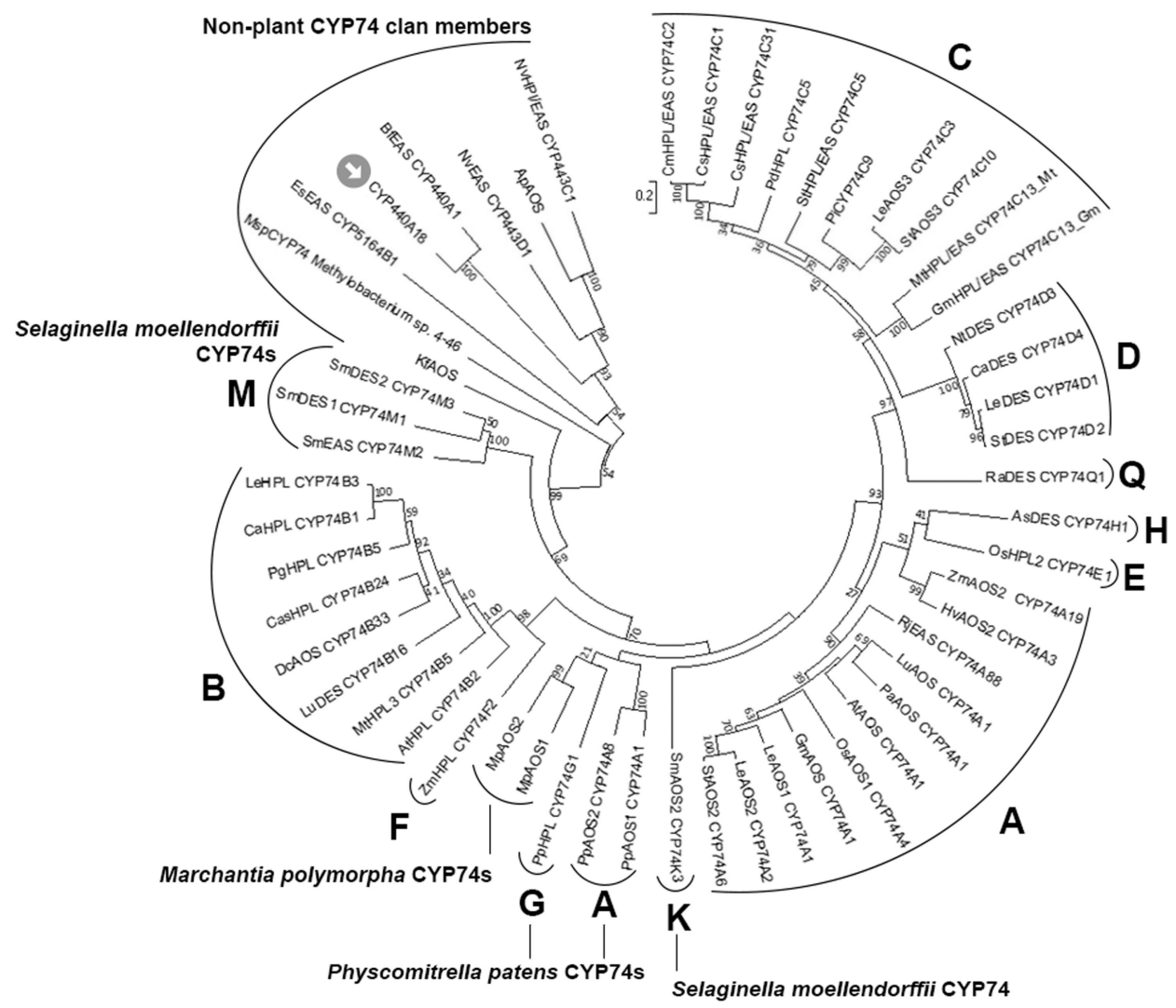

Figure 2. The unrooted phylogenetic tree of the CYP74 family. Classified CYP74 subfamilies are marked with their letter designations (A-H, K, M, and $\mathbf{Q})$. The CYP440A18 enzyme is marked by an arrow. The following CYP74 clan members were used for analysis: Ap, Acropora palmata; ApAOS, ACD42778.1; As, Allium sativum; AsDES (CYP74H1), CAI30435.1; At, Arabidopsis thaliana; AtAOS (CYP74A1), NP199079.1; AtHPL (CYP74B2), C74B2ARATH; Bb, Branchiostoma belcheri; BbEAS/AOS, XP_019641998.1; Bf, Branchiostoma floridae; BfEAS (CYP440A1), ACD88492.1; Ca, Capsicum annuum; CaHPL (CYP74B1), NP001311810.1; CaDES (CYP74D4), NP001311513.1; Cas, Camellia sinensis; CasHPL (CYP74B24), BAU24783.1; Cs, Cucumis sativus; CsHPL/EAS/AOS (CYP74C31), XP004137005.1; CsHPL/EAS (CYP74C1_Cs), NP001274399.1; Cm, Cucumis melo; CmHPL/EAS (CYP74C2), NP001284390.1; Dc, Daucus carota; DcAOS (CYP74B33), XP_017248700.1; Es, Ectocarpus siliculosus; EsEAS (CYP5164B1), APG42673.1; Gm, Glycine max; GmAOS (CYP74A1), NP001236432.1; GmHPL/EAS (CYP74C13_Gm), KRH29541.1; Hv, Hordeum vulgare, HvAOS2 (CYP74A3), CAB86384.1; Kf, Klebsormidium flaccidum; KfAOS, BAS32649.1; Le, Solanum lycopersicum; LeAOS1 (CYP74A1), CAB88032.1; LeAOS2 (CYP74A2), AAF67141.1; LeAOS3 (CYP74C3), NP001265949.1; LeHPL (CYP74B3), AAF67142.1; LeDES (CYP74D1), NP001234527.1; Lu, Linum usitatissimum; LuAOS (CYP74A1), P48417.1; LuDES (CYP74B16), ADP03054.2; Mp, Marchantia polymorpha; MpAOS1, BAS32647.1; MpAOS2, BAS32648.1; Msp, Methylobacterium sp. 4-46, WP012335549.1; Mt, Medicago truncatula; MtHPL/EAS (CYP74C13_Mt), XP003606860.1; MtHPL3 (CYP74B4), AAY30368.1; Nt, Nicotiana tabacum; NtDES (CYP74D3), NP001312606.1; Nv, Nematostella vectensis; NvHPl/EAS (CYP443C1); NvEAS (CYP443D1), XP_001636360.1; Os, Oryza sativa; OsAOS1 (CYP74A4), XP015631686.1; OsHPL2 (CYP74E1), EAY85033.1; Pa, Parthenium argentatum; PaAOS (CYP74A1), sp I Q40778.2; Pd, Prunus dulcis; PdHPL (CYP74C5), CAE18065.1; Pg, Psidium guajava; PgHPL (CYP74B5), AAK15070.1; Pi, Petunia inflata; PiCYP74C9, ABC75838.1; Pp, P. patens; PpAOS1 (CYP74A1), XP024380613.1; PpAOS2 (CYP74A8), XP024372097.1; PpHPL (CYP74G1), CAC86920.2; Ra, Ranunculus acris; RaDES (CYP74Q1), AJU57209.1; Rj, Ranunculus japonicus; RjEAS (CYP74A88), QCR70269.1; Sm, Selaginella moellendorffii; SmDES1 (CYP74M1), XP002979266.1; SmDES2 (CYP74M3), XP002964012.2; SmEAS (CYP74M2), EFJ26024.1; St, Solanum tuberosum; StAOS2 (CYP74A6), ABD15175.1; StAOS3 (CYP74C10), CAI30876.1; StHPL/EAS (CYP74C4), XP006365486.1; StDES (CYP74D2), NP001305517.1; Zm, Zea mays; ZmAOS1 (CYP74A19), AAR33048.1; ZmHPL (CYP74F2), NP_001105255.2. 


\subsection{Kinetics and Substrate Specificity of the Recombinant CYP440A18 Enzyme}

The recombinant CYP440A18 enzyme efficiently utilized all substrates used (9-HPOD, 9-HPOT, 13-HPOD, 13-HPOT, 15-HPETE, and 15-HPEPE). The recombinant CYP440A18 enzyme exhibited the $\mathrm{pH}$ optimum at $\mathrm{pH} 7.0$ (Figure 3).

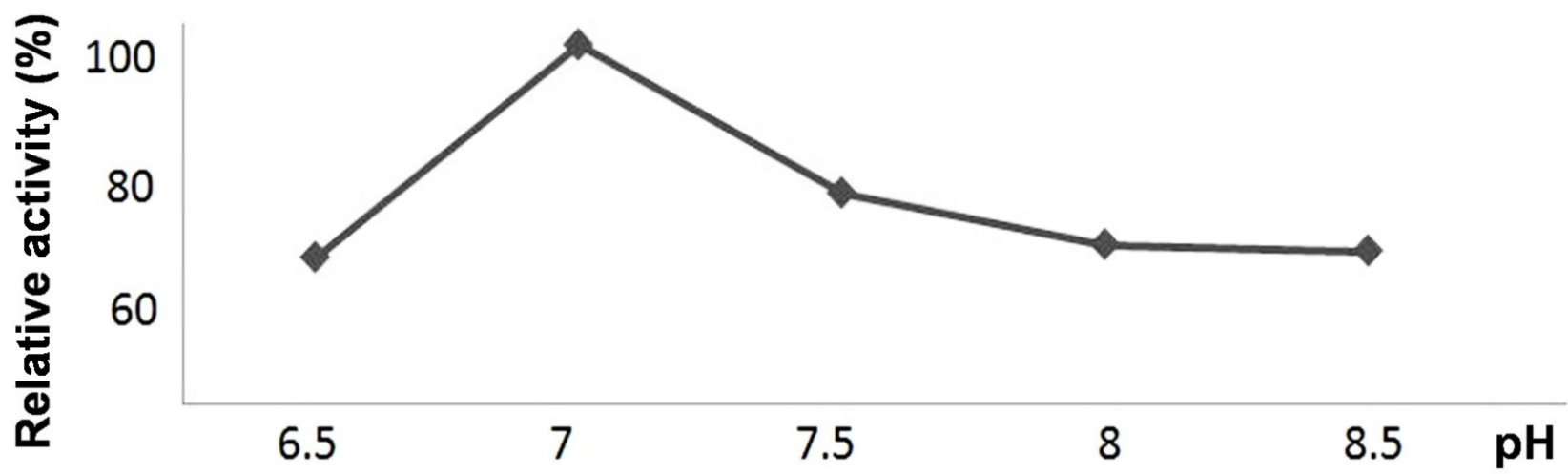

Figure 3. The $\mathrm{pH}$ dependences of catalytic activities of the recombinant CYP440A18 enzyme towards 13-HPOT.

Among C18 hydroperoxides, the CYP440A18 enzyme possessed the highest catalytic activity and affinity towards $13(S)$-HPOT (3-5 times higher than other $\mathrm{C}_{18}$ hydroperoxides) (see Table 1).

Table 1. Kinetic parameters of the recombinant CYP440A18 enzyme towards $C_{18}$ fatty acid hydroperoxides.

\begin{tabular}{ccccc}
\hline Substrate & $\boldsymbol{K}_{\boldsymbol{m}}, \boldsymbol{\mu \mathbf { M }}$ & $\boldsymbol{k}_{\text {cat }}, \mathbf{s}^{-\mathbf{1}}$ & $\begin{array}{c}\boldsymbol{k}_{\text {cat }} / \boldsymbol{K}_{\boldsymbol{m}} \boldsymbol{\prime} \\
\boldsymbol{\mu} \mathbf{M}^{\mathbf{- 1}} \cdot \mathbf{s}^{\mathbf{- 1}}\end{array}$ & Specificity, \% \\
\hline 13-HPOT & 17.6 & 431.8 & 24.5 & 100 \\
\hline 13-HPOD & 18.6 & 174.2 & 9.4 & 38.4 \\
\hline 9-HPOT & 31.8 & 247.9 & 7.8 & 31.8 \\
\hline 9-HPOD & 37.0 & 164.0 & 4.4 & 18.0 \\
\hline
\end{tabular}

As a whole, the CYP440A18 enzyme possessed higher substrate specificity towards hydroperoxides of $\omega 3$ fatty acids ( $\alpha$-linolenic and eicosapentaenoic acids) than hydroperoxides of $\omega 6$ fatty acids (linoleic and eicosatetraenoic acids).

\subsection{Analysis of Products of $\mathrm{C}_{18}$ Hydroperoxide Conversions by the CYP440A18 Enzyme}

The CYP440A18 enzyme was incubated with 13-HPOT, 13-HPOD, 9-HPOT, 9-HPOD, 15-HPEPE, and 15-HPETE. The $\mathrm{NaBH}_{4}$-reduced (as well as the non-reduced) products (Me/TMS) of incubations were analyzed by GC-MS. The structural formulae of the identified products of the CYP440A18 enzyme are presented at the Figure 4. 
<smiles>CC/C=C/C1OC1C(O)/C=C/CCCCCCCC(=O)O</smiles><smiles>CC/C=C/CC(O)C(O)C/C=C/CCCCCCCC(=O)O</smiles>

2<smiles>CC/C=C/CC(O)C(O)C/C=C/CCCCCCCC(=O)O</smiles>

$2 a / 2 b$<smiles>CCCCCC1OC1C(O)/C=C/CCCCCCCC(=O)O</smiles><smiles>CCCCCC(O)C(=O)CC=CCCCCCCCC(=O)O</smiles><smiles>CCCCCC(O)C(O)C/C=C/CCCCCCCC(=O)O</smiles><smiles>CC/C=C/C/C=C/C(O)C1OC1CCCCCCCC(=O)O</smiles><smiles>CC/C=C/C/C=C/CC(O)C(O)CCCCCCCC(=O)O</smiles><smiles>CCC=CCC=CCC(O)C(O)CCCCCCCC(=O)O</smiles><smiles>[3H]C(=O)CCCCCCCC1OC1/C=C/CCCCC</smiles><smiles>CCCCCC=CCC(=O)C(O)CCCCCCCC(=O)O</smiles>

8<smiles>CCCCCCC=CCC(O)C(O)CCCCCCCC(=O)OC(C)(C)C</smiles><smiles>CC/C=C/C1OC1C(O)/C=C/C/C=C/C/C=C/CCCC(=O)O</smiles><smiles>CC/C=C/CC(O)C(=O)C/C=C/C/C=C/C/C=C/CCCC(=O)O</smiles><smiles>CCC=CCC(O)C(O)CC=CCC=CCC=CCCC(=O)O</smiles><smiles>CCCCCC1OC1C(O)/C=C/C/C=C/C/C=C/CCCC(=O)O</smiles><smiles>CCCCCC(O)C(=O)C/C=C/C/C=C/C/C=C/CCCC(=O)O</smiles>

12<smiles>CCCCCC(O)C(O)C/C=C/C/C=C/C/C=C/CCCC(=O)O</smiles><smiles>CCC/C=C/CC1C(=O)CCC1CCCCCCC(=O)O</smiles>

13<smiles>CCCCCCC1CCC(O)C1CCCCCCCCC(=O)O</smiles>

Figure 4. The structural formulae of products of recombinant CYP440A18 enzyme incubations with different substrates: 1, 11-hydroxy-12,13-epoxy-9,15-octadecadienoic acid; 2, (9Z,15Z)-12-oxo-13-hydroxy-9,15-octadecadienoic acid ( $\alpha$-ketol); 2a/2b, threo/erythro 12,13-diols (12,13-dihydroxy-9,15-octadecadienoic acid); 3, 11-hydroxy-12,13-epoxy-9-octadecenoic acid; 4, (9Z)-12-oxo-13-hydroxy-9-octadecenoic acid ( $\alpha$-ketol); 4a/4b, threo/erythro 12,13-diols (12,13-dihydroxy-9-octadecenoic acid); 5, 9,10-epoxy-11-hydroxy-12,15-octadecadienoic acid; 6, (12Z,15Z)-9-hydroxy-10-oxo-12,15-octadecadienoic acid ( $\alpha$-ketol); 6a/6b, threo/erythro 9,10-diols (9,10-dihydroxy-12,15-octadecadienoic acid); 7, 9,10-epoxy-11-hydroxy-12-octadecenoic acid; 8, (12Z)-9-hydroxy-10-oxo-12-octadecenoic acid ( $\alpha$-ketol); 8a/8b, threo/erythro 9,10-diols (9,10-dihydroxy-12-octadecenoic acid); 9, 13-hydroxy-14,15-epoxy-5,8,11,17-eicosatetraenoic acid; 10, 14-oxo-15-hydroxy-5,8,11,17-eicosatetraenoic acid ( $\alpha$-ketol); 10a/10b, threo/erythro 14,15-diols (14,15-dihydroxy-5,8,11,17-eicosatetraenoic acid); 11, 13-hydroxy-14,15-epoxy5,8,11-eicosatrienoic acid; 12, 14-oxo-15-hydroxy-5,8,11-eicosatrienoic acid ( $\alpha$-ketol); 12a/12b, threo/erythro 14,15-diols (14,15dihydroxy-5,8,11-eicosatrienoic acid); 13, cis-12-oxo-10,15-phytodienoic acid; 14, dihomo-cis-12-oxo-3,6,10,15-phytodienoic acid; 15, dihomo-12-oxophytonoic acid. 
The main product of 13(S)-HPOT conversion by the CYP440A18 enzyme was compound 1, the mass spectrum of which (Me/TMS, Supplementary Materials Figure S1A) possessed $\mathrm{M}^{+}$at $m / z 396(0.1 \%),[\mathrm{M}-\mathrm{Me}]^{+}$at $m / z 381(0.5 \%)$, [M-pentenyl] ${ }^{+}$at $m / z 327(1 \%)$, $[\mathrm{M}-\mathrm{C} 12 / \mathrm{C} 18]^{+}$at $m / z 285(57 \%), m / z 155(18 \%), m / z 129(40 \%)$, and [TMS] ${ }^{+}$at $m / z 73(100 \%)$ (Figure 5A).

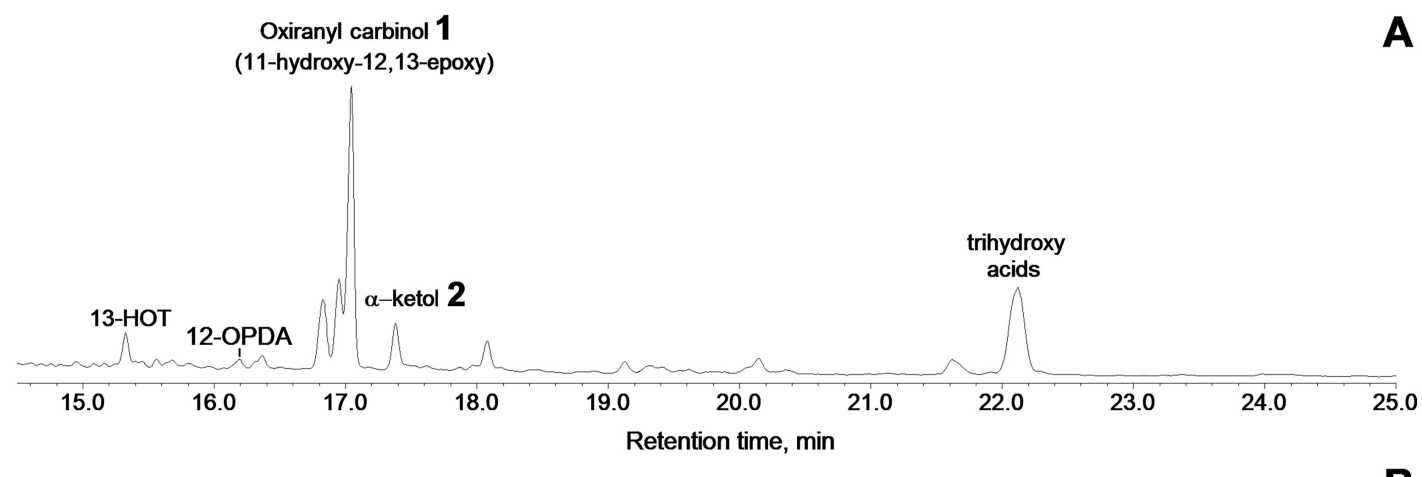

Oxiranyl carbinol 3

B

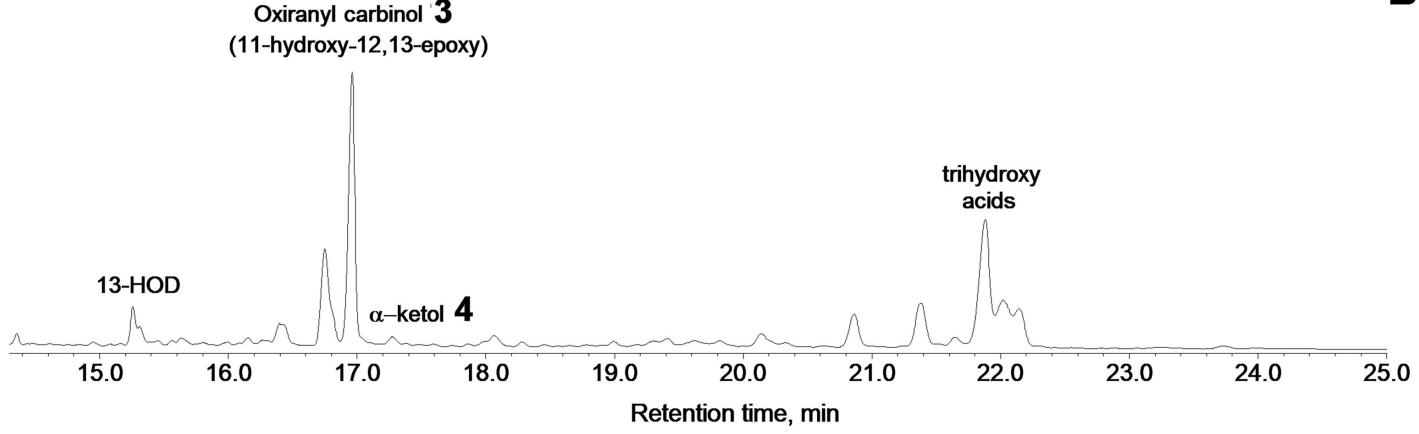

Oxiranyl carbinol 5

C
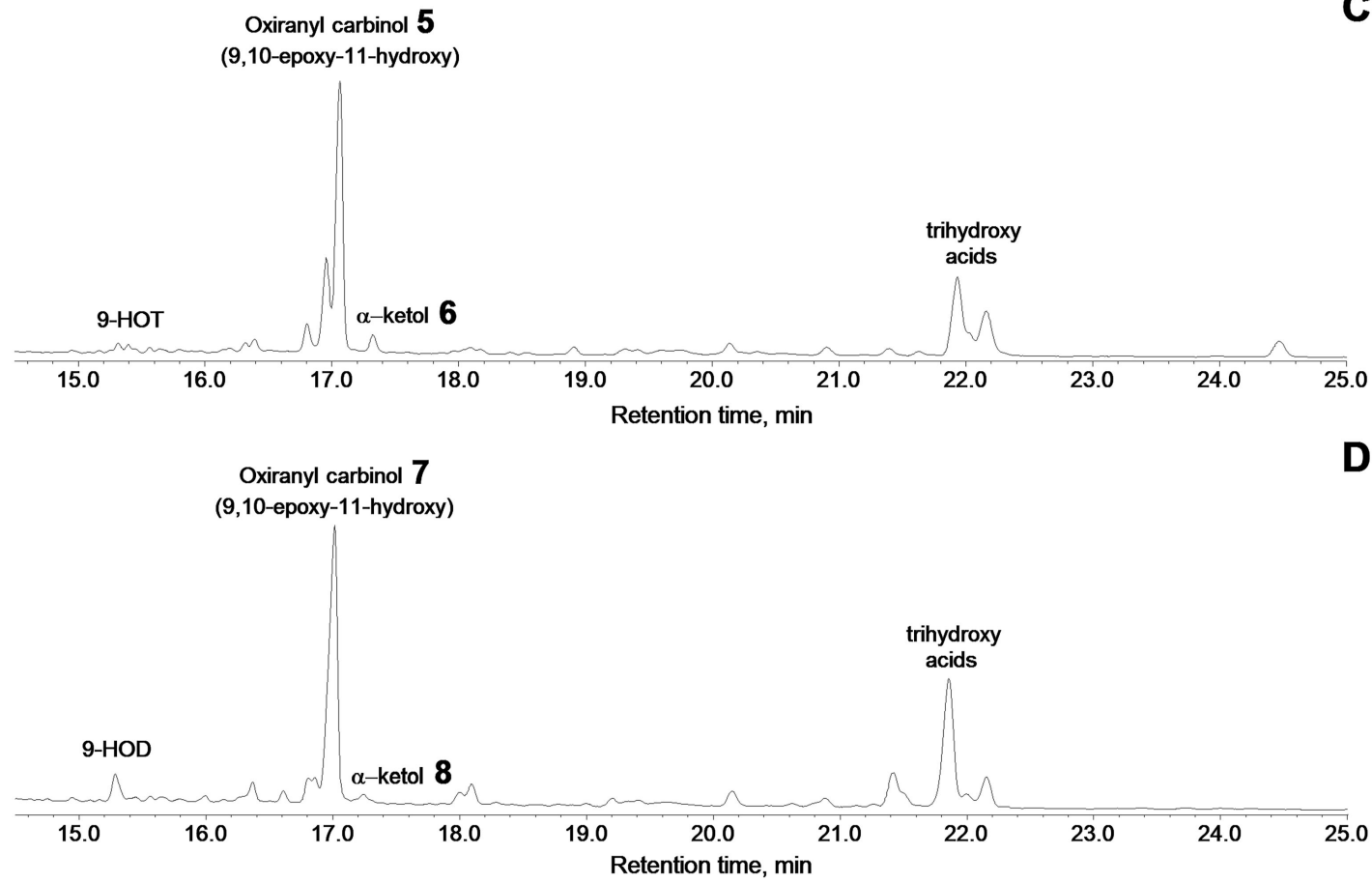

Figure 5. The total ion current GC-MS chromatograms of products (Me/TMS) of incubation of 13-HPOT (A), 13-HPOD (B), 9-HPOT (C), and 9-HPOD (D) with recombinant CYP440A18 enzyme. Conditions of incubation, extraction, derivatization, and analysis are described in the Materials and Methods section. The structural formulae of products are present at the Figure 4. 13-HOT, (9Z,11E,13S,15Z)-13-hydroxy-9,11,15-octadecatrienoic acid; 13-HOD, (9Z,11E,13S)-13-hydroxy-9,11octadecadienoic acid; 9-HOT, (9S,10E,12Z,15Z)-9-hydroxy-10,12,15-octadecatrienoic acid; 9-HOD, (9S,10E,12Z)-9-hydroxy10,12-octadecadienoic acid. 
The prominent fragment $[\mathrm{M}-\mathrm{C} 12 / \mathrm{C} 18]^{+}$at $\mathrm{m} / \mathrm{z} 285$ resulted from cleavage between oxirane and C11 [27]. The mass spectrum corresponded to that of $(9 Z, 12 R, 13 S, 15 Z)-11-$ hydroxy-12,13-epoxy-9,15-octadecadienoic acid. Catalytic hydrogenation of compound 1 over $\mathrm{PtO}_{2}$ followed by methylation and trimethylsilylation afforded the compound a mass spectrum corresponding to the structure of 11-hydroxy-12,13-epoxyoctadecanoic acid (Me/TMS), thus confirming the identification of product $\mathbf{1}$ as oxiranyl carbinol (9Z,12R,13S,15Z)-11-hydroxy-12,13-epoxy-9,15-octadecadienoic acid (Me/TMS).

The additional product of this reaction was the $\alpha$-ketol 2 (Figures 5A and S1B)(9Z,15Z)-12-oxo-13-hydroxy-9,15-octadecadienoic acid [30,31], which upon $\mathrm{NaBH}_{4}$ reduction was transformed to the diastereomeric pair (threo and erythro) of 12,13-diol (12,13dihydroxy-9,15-octadecadienoic acid, Me/TMS) $\mathbf{2} \mathbf{a}$ and $\mathbf{2} \mathbf{b}$, having the identical mass spectral patterns (Figure S1C): $\mathrm{M}^{+}$at $m / z 470(0.3 \%),[\mathrm{M}-\mathrm{Me}]^{+}$at $m / z 455(0.6 \%),[\mathrm{M}-\mathrm{MeOH}]^{+}$ at $m / z 439(1 \%),[\mathrm{M}-\mathrm{TMSOH}-\mathrm{H}]^{+}$at $\mathrm{m} / z 379(0.3 \%),[\mathrm{M}-\mathrm{C} 13 / \mathrm{C} 18]^{+}$at $\mathrm{m} / z 299(13 \%)$, [M$\mathrm{C} 1 / \mathrm{C} 11]^{+}$at $m / z 273(10 \%),[\mathrm{M}-\mathrm{C} 12 / \mathrm{C} 18+\mathrm{TMS}]^{+}$at $m / z 270(7 \%),[275-\mathrm{TMSOH}]^{+}$at $\mathrm{m} / \mathrm{z}$ $183(18 \%),[\mathrm{M}-299]^{+}$at $m / z 171(24 \%), m / z 143(3 \%)$, and $[\mathrm{TMS}]^{+}$at $\mathrm{m} / z 73(100 \%)$.

Profiles of conversions of other $\mathrm{C}_{18}$ hydroperoxides by the CYP440A18 enzyme looked similar to that of 13(S)-HPOT conversion. Thus, incubation of 13(S)-HPOD (Figure 5B) with the CYP440A18 enzyme resulted in formation of main product 3, the mass spectrum of which (Me/TMS, Figure S2A) exhibited $\mathrm{M}^{+}$at $m / z 398(0.2 \%),[\mathrm{M}-\mathrm{Me}]^{+}$at $\mathrm{m} / z 383$ $(2 \%)$, [M-n-pentyl] ${ }^{+}$at $m / z 327(1.5 \%),[\mathrm{M}-\mathrm{C} 12 / \mathrm{C} 18]^{+}$at $m / z 285(86 \%)$, and [TMS] $^{+}$at $\mathrm{m} / \mathrm{z} 73(100 \%)$. The mass spectrum differed from that described above in fragment [M$\mathrm{Me}]^{+}$. Catalytic hydrogenation of product 3 over $\mathrm{PtO}_{2}$ followed by methylation and trimethylsilylation yielded saturated analogue also described above. As a whole, the mass spectral data indicated the structure of 11-hydroxy-12,13-epoxy-9-octadecenoic acid (Me/TMS) for compound 3. The minor product of this conversion was the $\alpha$-ketol 4, (9Z)-12-oxo-13-hydroxy-9-octadecenoic acid (Figure 5B and Figure S2B) [32], which upon $\mathrm{NaBH}_{4}$ reduction was transformed to the diastereomeric pair (threo and erythro) of 12,13diols $4 \mathbf{a}$ and $\mathbf{4 b}$, having identical mass spectral patterns (Figure S2C): $\mathbf{M}^{+}$at $m / z 472(1.4 \%$ ), $\left[\mathrm{M}-\mathrm{Me}^{+}\right.$at $m / z 457(2 \%),[\mathrm{M}-\mathrm{MeOH}]^{+}$at $m / z 441(2 \%),[\mathrm{M}-\mathrm{TMSOH}-\mathrm{H}]^{+}$at $m / z 381(2 \%)$, [M-C13/C18] $]^{+}$at $m / z 299(14 \%),[\mathrm{M}-\mathrm{C} 1 / \mathrm{C} 11]^{+}$at $\mathrm{m} / z 275(15 \%),[\mathrm{M}-\mathrm{C} 12 / \mathrm{C} 18+\mathrm{TMS}]^{+}$at $\mathrm{m} / \mathrm{z} 270(7 \%),[275-\mathrm{TMSOH}]^{+}$at $\mathrm{m} / \mathrm{z} 185(17 \%),[\mathrm{M}-299]^{+}$at $\mathrm{m} / \mathrm{z} 173(35 \%), \mathrm{m} / z 143(10 \%)$, and [TMS] $]^{+}$at $m / z 73(100 \%)$.

Conversion of $9(S)$-HPOT by the CYP440A18 enzyme resulted in formation of compounds 5 and 6 (Figure 5C). The electron impact mass spectrum of main product 5 (Me/TMS, Figure S3A) exhibited [M-Me] ${ }^{+}$at $m / z 381(0.3 \%),[\mathrm{M}-\mathrm{Me}-\mathrm{MeOH}]^{+}$at $m / z$ $349(0.1 \%),[\mathrm{M}-\mathrm{TMSOH}]^{+}$at $m / z 306(1 \%),[\mathrm{M}-\mathrm{TMSOH}]^{+}$at $m / z 197(27 \%), m / z 131(38 \%)$, $\mathrm{m} / \mathrm{z} 107(64 \%)$, and [TMS] $]^{+}$at $\mathrm{m} / z 73(100 \%)$. Catalytic hydrogenation of product 5 over $\mathrm{PtO}_{2}$ followed by methylation and trimethylsilylation afforded the above-described product, the mass spectrum of which corresponded to that of 9,10-epoxy-11-hydroxyoctadecanoic acid. The data obtained enabled the identification of compound 5 as 9,10-epoxy-11-hydroxy12,15-octadecadienoic acid. Additionally, this reaction afforded the $\alpha$-ketol 6, $(12 Z, 15 Z)$ 9-hydroxy-10-oxo-12,15-octadecadienoic acid (Figure 5C and Figure S3B), which upon $\mathrm{NaBH}_{4}$ reduction was converted to the diastereomeric pair of 9,10-diols $\mathbf{6} \mathbf{a}$ and $\mathbf{6} \mathbf{b}$, possessing the identical mass spectral patterns (Figure S3C) exhibiting $\mathrm{M}^{+}$at $m / z 470(0.7 \%)$, [M-Me] $^{+}$at $m / z 455(0.4 \%),[\mathrm{M}-\mathrm{MeO}]^{+}$at $m / z 439(1 \%),[\mathrm{M}-\mathrm{C} 11 / \mathrm{C} 18]^{+}$at $m / z 361(4 \%)$,

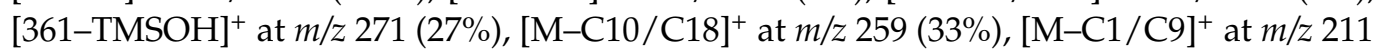
$(7 \%), m / z 155(39 \%), m / z 129(13 \%), m / z 109(25 \%)$, [CH2 = $\left.\mathrm{O}^{+}-\mathrm{TMS}\right]$ at $m / z 103(17 \%)$, and [TMS] $^{+}$at $m / z 73(100 \%)$.

The GC-MS analyses of $\mathrm{NaBH}_{4}$-reduced products (Me/TMS) of the CYP440A18 enzyme incubation with 9(S)-HPOD revealed a predominant product 7 and minor peak 8 (Figure 5D). The mass spectrum of the main product 7 (Me/TMS, Figure S4A) exhibited $\mathrm{M}^{+}$ at $m / z 398(0.2 \%),[\mathrm{M}-\mathrm{Me}]^{+}$at $m / z 383(1 \%),[\mathrm{M}-\mathrm{C} 1 / \mathrm{C} 8]^{+}$at $m / z 241(3 \%),[\mathrm{M}-\mathrm{C} 1 / \mathrm{C} 9]^{+}$at $\mathrm{m} / \mathrm{z} 212(2 \%),[\mathrm{M}-\mathrm{C} 1 / \mathrm{C} 10]^{+}$at $\mathrm{m} / \mathrm{z} 199(100 \%)$, and [TMS] ${ }^{+}$at $m / z 73(100 \%)$. A prominent peak at $\mathrm{m} / \mathrm{z} 199$ indicated the presence of an oxiranyl carbinol function with oxirane at 
C9/C10 and a secondary alcohol moiety (TMS) at C11. The mass spectrum corresponded to that of 9,10-epoxy-11-hydroxy-12-octadecenoic acid (Me/TMS) [17]. Catalytic hydrogenation of product 7 over $\mathrm{PtO}_{2}$ followed by methylation and trimethylsilylation afforded product, mass spectrum of which indicated a structure of 9,10-epoxy-11-hydroxyoctadecanoic acid (Me/TMS). Thus, the mass spectral data substantiated the structure of 9,10-epoxy-11hydroxy-12-octadecenoic acid for compound 7. Additionally, this reaction afforded the $\alpha$-ketol 8, (12Z)-9-hydroxy-10-oxo-12-octadecenoic acid (Figures 5D and S4B) [33], which upon $\mathrm{NaBH}_{4}$ reduction was converted to the diastereomeric pair of 9,10-diols $\mathbf{8 a}$ and $\mathbf{8 b}$, possessing the identical mass spectral patterns (Figure S4C) exhibiting $\mathrm{M}^{+}$at $\mathrm{m} / \mathrm{z} 472(2 \%)$, [M-Me] $^{+}$at $m / z 457(2 \%),[\mathrm{M}-\mathrm{MeO}]^{+}$at $m / z 441(2 \%),[\mathrm{M}-\mathrm{C} 11 / \mathrm{C} 18]^{+}$at $m / z 361(3 \%)$, $[\mathrm{M}-\mathrm{C} 10 / \mathrm{C} 18+\mathrm{TMS}]^{+}$at $\mathrm{m} / \mathrm{z} 332(2 \%),[361-\mathrm{TMSOH}]^{+}$at $\mathrm{m} / \mathrm{z} 271(12 \%),[\mathrm{M}-\mathrm{C} 10 / \mathrm{C} 18]^{+}$at $m / z 259(13 \%),[\mathrm{M}-\mathrm{C} 1 / \mathrm{C} 9]^{+}$at $m / z 213(9 \%), m / z 155(25 \%), m / z 129(32 \%), m / z 109(30 \%)$ [CH2 $\left.=\mathrm{O}^{+}-\mathrm{TMS}\right]$ at $m / z 103(16 \%)$, and [TMS] $]^{+}$at $m / z 73(100 \%)$.

Among the products of the conversion of all C18 hydroperoxides studied by the CYP440A18 enzyme, trihydroxy acids, products of spontaneous hydrolysis of oxiranyl carbinols (epoxyalcohols), were also detected (Figure 5).

\subsection{Analysis of Products of $C_{20}$ Hydroperoxide Conversions by the CYP440A18 Enzyme}

Results of C20 hydroperoxide conversions by the CYP440A18 enzyme appeared similar to those of $\mathrm{C} 18$ hydroperoxide conversions. Thus, incubation of 15(S)-HPEPE (Figure 6A) with the CYP440A18 enzyme resulted in formation of main product 9 , the mass spectrum of which (Me/TMS, Figure $6 \mathrm{~B}$ ) exhibited $\mathrm{M}^{+}$at $\mathrm{m} / \mathrm{z} 420(0.6 \%),[\mathrm{M}-\mathrm{Me}]^{+}$at $\mathrm{m} / \mathrm{z}$ $405(0.6 \%),[\mathrm{M}-\mathrm{C} 16 / \mathrm{C} 20]^{+}$at $m / z 309(2 \%),[\mathrm{M}-\mathrm{C} 1 / \mathrm{C} 15]^{+}$at $m / z 142(29 \%)$, and [TMS] $^{+}$at $m / z 73(100 \%)$.

Catalytic hydrogenation of product 9 over $\mathrm{PtO}_{2}$ followed by methylation and trimethylsilylation yielded saturated analogue, the mass spectrum of which corresponded to that of 13-hydroxy-14,15-epoxy-eicosanoic acid (Me/TMS). As a whole, the mass spectral data indicated the structure of 13-hydroxy-14,15-epoxy-5,8,11,17-eicosatetraenoic acid (Me/TMS) for compound 9. The minor product of this conversion was the $\alpha$-ketol 10 (Figure 6C), 14-oxo-15-hydroxy-5,8,11,17-eicosatetraenoic acid (Me/TMS), which upon the $\mathrm{NaBH}_{4}$ reduction was transformed to the diastereomeric pair (threo and erythro) of 14,15-diols 10a and 10b (Figure S4D), having the identical mass spectral patterns: $\mathrm{M}^{+}$at $m / z 494(1 \%)$, $[\mathrm{M}-\mathrm{Me}]^{+}$at $m / z 479(1 \%),[\mathrm{M}-\mathrm{MeOH}]^{+}$at $m / z 463(1 \%),[\mathrm{M}-\mathrm{C} 16 / 20]^{+}$at $m / z 425(1.5 \%)$, [425-TMSOH] $^{+}$at $m / z 335(4 \%),[\mathrm{M}-\mathrm{C} 14 / \mathrm{C} 20]^{+}$at $m / z 273(6 \%),[273-\mathrm{TMSOH}]^{+}$at $m / z 183$ $(18 \%),[\mathrm{M}-\mathrm{C} 15 / \mathrm{C} 20]^{+}$at $\mathrm{m} / \mathrm{z} 171(18 \%)$, and TMS $^{+}$at $\mathrm{m} / \mathrm{z} 73(94 \%)$.

The main product of 15(S)-HPETE conversion (Figure 7A) by the CYP440A18 enzyme was compound 11, the mass spectrum of which (Me/TMS, Figure 7B) possessed $\mathrm{M}^{+}$at $\mathrm{m} / \mathrm{z}$ $422(0.1 \%),[\mathrm{M}-\mathrm{Me}]^{+}$at $\mathrm{m} / z 407(0.2 \%),[\mathrm{M}-\mathrm{C} 14 / \mathrm{C} 20]^{+}$at $\mathrm{m} / z 309(7 \%),[309-\mathrm{TMSOH}]^{+}$at

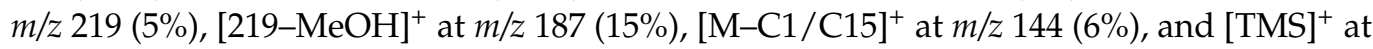
$m / z 73(100 \%)$. 

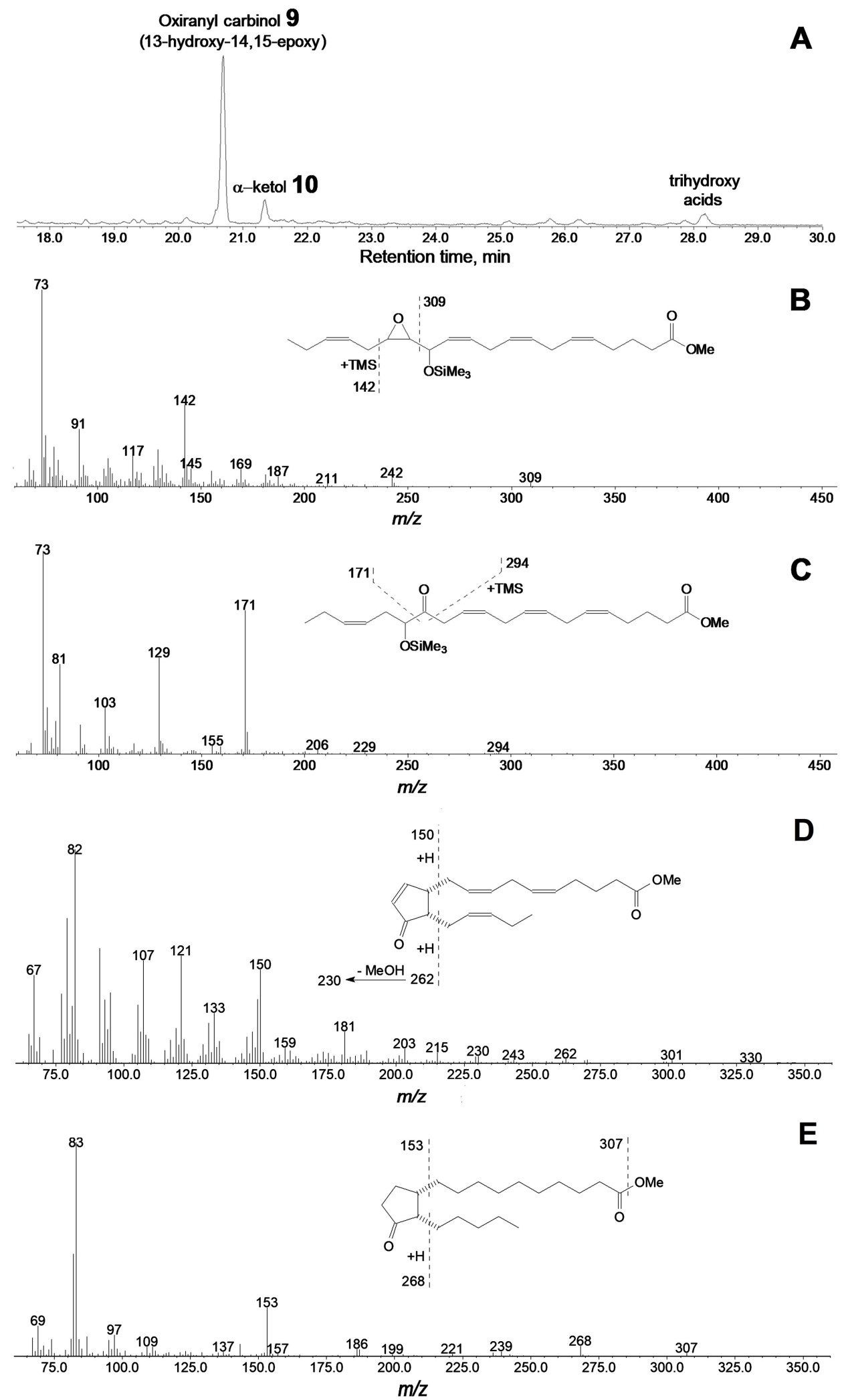

Figure 6. The result of GC-MS analysis of products (Me/TMS) of 15-HPEPE incubation with recombinant CYP440A18 enzyme. (A) The total ion current GC-MS chromatogram of products (Me/TMS) of 15HPEPE incubation with recombinant enzyme. (B) The mass spectrum and fragmentation scheme (inset) for product 9. (C) The mass spectrum and fragmentation scheme (inset) for product 10. (D) The mass spectrum and fragmentation scheme (inset) for product 14. (E) The mass spectrum and fragmentation scheme (inset) for product 15. Conditions of incubation, extraction, derivatization, and analysis are described in the Materials and Methods section. Structures of products are presented in Figure 4. 

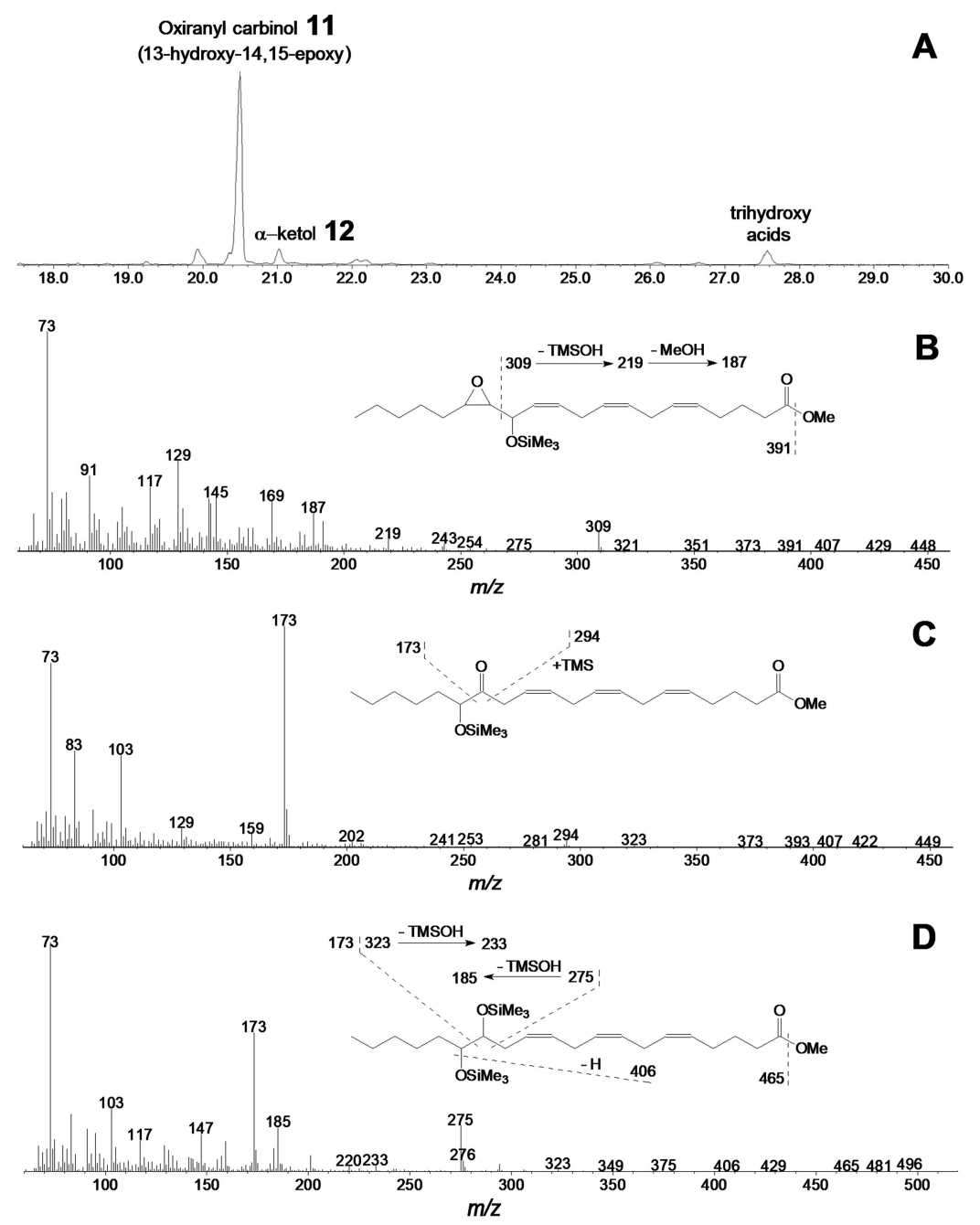

Figure 7. The result of GC-MS analysis of products (Me/TMS) of 15-HPETE incubation with recombinant CYP440A18 enzyme. (A) The total ion current GC-MS chromatogram of products (Me/TMS) of 15-HPETE incubation with recombinant enzyme. (B) The mass spectrum and fragmentation scheme (inset) for product 11. (C) The mass spectrum and fragmentation scheme (inset) for product 12. (D) The mass spectrum and fragmentation scheme (inset) for product 12a. Conditions of incubation, extraction, derivatization, and analysis are described in the Materials and Methods section. Structures of products are presented in Figure 4.

The mass spectrum corresponded to that of 13-hydroxy-14,15-epoxy-8,11,17-eicosatrienoic acid (Me/TMS). Catalytic hydrogenation of compound 11 over $\mathrm{PtO}_{2}$ followed by methylation and trimethylsilylation afforded saturated analogue 13-hydroxy-14,15-epoxy-eicosanoic acid (Me/TMS), described above. Thus, the mass-spectral data confirmed the identification of product 11 as oxiranyl carbinol 13-hydroxy-14,15-epoxy-5,8,11-eicosatrienoic acid (Me/TMS). The minor product of this reaction was the $\alpha$-ketol 12 (Figure 7C)-14oxo-15-hydroxy-5,8,11-eicosatrienoic acid (Me/TMS), which upon $\mathrm{NaBH}_{4}$ reduction was transformed to the diastereomeric pair (threo and erythro) of 14,15-diol (14,15-dihydroxy5,8,11-eicosatrienoic acid, Me/TMS) 12a and $\mathbf{1 2 b}$ (Figure 7D), having identical mass spectral patterns: $\mathrm{M}^{+}$at $m / z 496(0.4 \%),[\mathrm{M}-\mathrm{Me}]^{+}$at $m / z 481(0.3 \%),[\mathrm{M}-\mathrm{MeO}]^{+}$at $m / z 465(0.4 \%)$, [M-TMSOH] $^{+}$at $m / z 406(0.5 \%),[\mathrm{M}-\mathrm{C} 15 / \mathrm{C} 20]^{+}$at $m / z 323(1.4 \%),[\mathrm{M}-\mathrm{C} 14 / \mathrm{C} 20]^{+}$at $m / z$ $275(20 \%),[323-\mathrm{TMSOH}]^{+}$at $\mathrm{m} / \mathrm{z} 233(3 \%),[275-\mathrm{TMSOH}]^{+}$at $\mathrm{m} / \mathrm{z} 185(20 \%),[\mathrm{M}-\mathrm{C} 1 / \mathrm{C} 14]^{+}$ at $m / z 173(61 \%)$, and [TMS] ${ }^{+}$at $m / z 73(100 \%)$. 
2.5. Formation of Cyclopentenones via Cyclization of Allene Oxides Biosynthesized from 13-HPOT and 15-HPEPE

It is noteworthy that the conversions of 13-HPOT and 15-HPEPE by CYP440A18 afforded not only $\alpha$-ketols but also the cis-cyclopentenones 13 (Figure 5A) and 14 (Figure 6A), respectively. The mass spectrum of compound $13(\mathrm{Me})$ possessed the following fragments: $\mathrm{M}^{+}$at $m / z 306(7 \%),[\mathrm{M}-\mathrm{MeO}]^{+}$at $\mathrm{m} / z 275(12 \%)$, [M-Et-MeOH] ${ }^{+}$at $m / z 245(13 \%)$, [M$\mathrm{C} 14 / \mathrm{C} 18+\mathrm{H}]^{+}$at $m / z 238(35 \%),[238-\mathrm{MeOH}]^{+}$at $m / z 206(11 \%),[\mathrm{M}-\mathrm{C} 1 / \mathrm{C} 6]^{+}$at $m / z 177$ (18\%), [M-C1/C7] at $\mathrm{m} / z 163(36 \%),[\mathrm{M}-\mathrm{C} 1 / \mathrm{C} 8]^{+}$at $\mathrm{m} / \mathrm{z} 149(31 \%), \mathrm{m} / \mathrm{z} 135(26 \%), \mathrm{m} / \mathrm{z}$ $121(39 \%), m / z 107(74 \%), m / z 96(99 \%)$, and $m / z 95(100 \%)$. The mass spectrum matched that of cyclopentenone 12-oxo-10,15-phytodienoic acid [34], the product of cyclization of allene oxide, the primary product of AOS reaction. The mass spectrum of product $14(\mathrm{Me}$, Figure 6D) possessed the following fragments: $\mathrm{M}^{+}$at $m / z 330(0.2 \%),[\mathrm{M}-\mathrm{Et}]^{+}$at $m / z 301$ $(2 \%),[\mathrm{M}-\mathrm{MeO}]^{+}$at $m / z 299(1 \%),[301-\mathrm{MeO}]^{+}$at $m / z 270(2 \%),[301-\mathrm{MeOH}]^{+}$at $m / z 269$ $(2 \%),[\mathrm{M}-\mathrm{C} 16 / \mathrm{C} 20+\mathrm{H}]^{+}$at $\mathrm{m} / \mathrm{z} 262(2 \%),[262-\mathrm{MeOH}]^{+}$at $\mathrm{m} / \mathrm{z} 230(4 \%), \mathrm{m} / \mathrm{z} 203(7 \%)$,

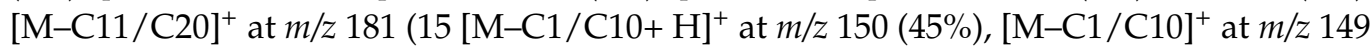
(30\%), $m / z 121(51 \%), m / z 107(48 \%), m / z 91(53 \%)$, and $m / z 82$ (100\%). To our knowledge, no spectral data for compound $\mathbf{1 4}$ have been described yet, except the partial MS data reported by Ziegler et al. (1999) [35]. For further structural approval, we hydrogenated the compound $14(\mathrm{Me})$ over $\mathrm{PtO}_{2}$. Hydrogenated product 15 exhibited the following mass spectral patterns (Figure 6E): $\mathrm{M}^{+}$at $m / z 338(0.04 \%),[\mathrm{M}-\mathrm{MeO}]^{+}$at $\mathrm{m} / \mathrm{z} 307(2 \%),[\mathrm{M}-\mathrm{C} 16 / \mathrm{C} 20+\mathrm{H}]^{+}$ at $m / z 268(6 \%),[268-\mathrm{MeOH}]^{+}$at $m / z 236(2 \%), m / z 187(3 \%), m / z 187(4 \%),[\mathrm{M}-\mathrm{C} 1 / \mathrm{C} 10]^{+}$ at $m / z 153(25 \%), m / z 143(4 \%)$, and $m / z 83(100 \%)$, thus allowing for the identification of hydrogenation product $\mathbf{1 5}$ and the original compound $\mathbf{1 4}$ as the saturated cyclopentanone dihomo-12-oxophytonoic acid and dihomo-cis-12-oxo-3,6,10,15-phytotetraenoic acid (having totally four double bonds), respectively.

Ratio of different reaction products of the CYP440A18 enzyme is summarized in Table 2. The products were quantified by integration of the total ion current GC-MS chromatograms.

Table 2. Quantitation of the main products of hydroperoxide conversions by the CYP440A18 enzyme.

\begin{tabular}{cccc}
\hline Substrate & $\boldsymbol{\alpha}$-Ketols, $\%$ & Cyclopentenones, $\%$ & Oxiranyl Carbinols, $\%$ \\
\hline 15-HPEPE $(\omega 3)$ & 17.1 & tr. $^{*}$ & 82.9 \\
\hline 15-HPETE $(\omega 6)$ & 6.3 & n.d. $^{* *}$ & 93.7 \\
\hline 13-HPOT $(\omega 3)$ & 17.4 & 3.7 & 78.9 \\
\hline 13-HPOD $(\omega 6)$ & 2.3 & n.d. & 97.7 \\
\hline 9-HPOT $(\omega 3)$ & 5.2 & n.d. & 94.8 \\
\hline 9-HPOD $(\omega 6)$ & 3.4 & n.d. & 96.6 \\
\hline tr. ${ }^{*}$, trace amount; n.d. ${ }^{* *}$, not detected. & &
\end{tabular}

\section{Discussion}

The described results revealed a dual epoxyalcohol synthase/allene oxide synthase activity of the recombinant protein CYP440A18 of B. belcheri. On the other hand, the CYP440A18 exhibited neither HPL nor DES side activities. Thus, a name BbEAS/AOS was ascribed to the enzyme. The major products of the BbEAS/AOS were oxiranyl carbinols such as compound 1 . The same products are biosynthesized by BfEAS (CYP440A1) of the lancelet B. floridae, as well as NvEAS (CYP443D1) and NvHPL/EAS (CYP443C1) of the starlet sea anemone $N$. vectensis $[15,23,25]$. It is noteworthy that the EASs of flowering plants [17,18,20], as well as the EsEAS (CYP5164B1) of brown alga E. siliculosus [17], mainly produce the $\mathrm{C} 10$ epimer of compound $\mathbf{1}$ (with trans-epoxide ring). In contrast to dedicated EASs such as BfEAS (CYP440A1), NvEAS (CYP443D1), NvHPL/EAS (CYP443C1), and EsEAS (CYP5164B1), the BbEAS/AOS also possessed an AOS activity producing the considerable yields of $\alpha$-ketols. Peculiarly, the hydroperoxides of $\omega 3$ fatty acids (13-HPOT 
and 15-HPEPE) afforded the higher proportions of AOS products upon incubations with BbEAS/AOS than all other hydroperoxides. Furthermore, the conversions of 13-HPOT and 15-HPEPE afforded the minorities of corresponding cyclopentenones, cis-12-oxo-10,15phytodienoic acid and dihomo-cis-12-oxo-3,6,10,15-phytodienoic acid, respectively, along with $\alpha$-ketols and epoxyalcohols. In contrast, $\alpha$-ketols were the sole AOS products of conversions of all other tested hydroperoxides.

Allene oxides (the primary AOS products) cyclization to cyclopentenones depends on the double bond in the $\beta, \gamma$-position towards the oxirane [36,37]. In other words, this $\beta, \gamma$ double bond (the $\omega 3$ double bond in allene oxides formed from 13-HPOT and 15-HPEPE) shows the effect of neighboring group participation (anchimeric assistance) elevating the cyclization rate $[36,37]$. The recent DFT modelling revealed that the double bond-assisted oxirane opening is the rate-limiting step of the whole conversion of allene oxide to cyclopentenone [37]. Similarly, the higher outcome of the AOS (dehydrase) products upon the BbEAS/AOS incubations with 13-HPOT and 15-HPEPE (compared to 13-HPOD and 15-HPETE) suggests the impact of $\omega 3$ double bond on the conversion of the epoxyallylic radical intermediate. Presumably, the presence of $\omega 3$ double bond facilitates the elimination of hydrogen at the oxirane to form allene oxide. Similarly, the LuDES (CYP74B16) dehydrates the 13-HPOT predominantly to divinyl ether ( $\omega 5 Z$ )-etherolenic acid, while 13-HPOD is largely isomerized to the hemiacetal (the HPL product) [29]. These observations indicate that the $\omega 3$ double bond affects the specificity of product formation by CYP74 clan enzymes.

The BbEAS/AOS is the second CYP74 clan member found in Chordata after the BfEAS (CYP440A1) of the lancelet Branchiostoma floridae [15]. At the same time, it is the first enzyme of Chordata possessing AOS activity. Overall, it is the second CYP74 clan enzyme in Metazoa possessing AOS activity, after the previously described allene oxide synthase ApAOS of stony coral A. palmata [15]. Besides the CYP74 clan proteins, there is a distinct kind of fatty acid hydroperoxide-metabolizing detected in soft corals and cyanobacteria. These are the catalase-related haemoproteins, for instance, the AOSs of soft corals Plexaura homomalla [38], Gersemia fruticosa [39], Capnella imbricata [40], and Acaryochloris marina [41] (see [42] for a review). All these enzymes are the fusion proteins consisting of the catalase and lipoxygenase domains. Thus, the detection of BbEAS/AOS adds more intricacy to the complex picture of oxylipin biosynthesis pathways in Chordata.

\section{Concluding Remarks}

1. The full-length coding sequence of Branchiostoma belcheri CYP440A18 enzyme has been expressed in Escherichia coli cells.

2. The recombinant CYP440A18 converted 9- and 13-hydroperoxides of linoleic and $\alpha$ linolenic acids, as well as 15 -hydroperoxides of eicosatetraenoic and eicosapentaenoic acids into the oxiranyl carbinols (EAS products) and $\alpha$-ketols (AOS products). For example, the CYP440A18 converted the preferred substrate, 13-hydroperoxide of $\alpha$ linolenic acid, into $(9 Z, 11 R, 12 R, 13 S, 15 Z)$-11-hydroxy-12,13-epoxy-9,15-octadecadienoic acid (EAS product) and 12-oxo-13-hydroxy-9,15-octadecadienoic acid (AOS product). Thus, the enzyme possessed dual epoxyalcohol synthase/allene oxide synthase activity.

3. Along with $\alpha$-ketols, 13-HPOT and 15-HPEPE yielded little amounts of cyclopentenones, cis-12-oxo-10,15-phytodienoic and dihomo-cis-12-oxo-3,6,10,15-phytotetraenoic acids, respectively.

4. The described BbEAS/AOS (CYP440A18) is the first epoxyalcohol synthase/allene oxide synthase (CYP74 clan) found in Chordata.

\section{Materials and Methods}

\subsection{Materials}

Linoleic, $\alpha$-linolenic, eicosatetraenoic, and eicosapentaenoic acids, as well as the soybean lipoxygenase type $\mathrm{V}$, were purchased from Sigma. $\mathrm{NaBH}_{4}$ and silylating reagents were purchased from Fluka (Buchs, Switzerland). (9S,10E,12Z)-9-Hydroperoxy-10,12- 
octadecadienoic (9-HPOD) and (9S,10E,12Z,15Z)-9-hydroperoxy-10,12,15-octadecatrienoic (9-HPOT) acids were prepared by incubation of linoleic and $\alpha$-linolenic acids, respectively, with the recombinant maize 9-lipoxygenase (GeneBank: AAG61118.1) [43] at $0{ }^{\circ} \mathrm{C}, \mathrm{Na}$ phosphate buffer $(100 \mathrm{mM}, \mathrm{pH} 6.0)$, under continuous oxygen bubbling. (9Z,11E,13S)-13Hydroperoxy-9,11-octadecadienoic (13-HPOD), (9Z,11E,13S,15Z)-13-hydroperoxy-9,11,15octadecatrienoic (13-HPOT), (5Z,8Z,11Z,13E,15S)-13-hydroperoxy-5,8,11,13-eicosatetraenoic (15-HPETE), and (5Z,8Z,11Z,13E,15S,17Z)-13-hydroperoxy-5,8,11,13,17-eicosapentaenoic (15-HPEPE) acids were obtained by incubation of linoleic, $\alpha$-linolenic, eicosatetraenoic, and eicosapentaenoic acids, respectively, with the soybean lipoxygenase type $\mathrm{V}$ at $23^{\circ} \mathrm{C}$, Tris- $\mathrm{HCl}$ buffer ( $50 \mathrm{mM}, \mathrm{pH} 9.0$ ), under continuous oxygen bubbling. The extracted hydroperoxides (as free carboxylic acids) were purified by normal phase HPLC (NP-HPLC) on the Kromasil Si columns $(7 \mu \mathrm{m} ; 4.0 \times 250 \mathrm{~mm}$; Elsico, Moscow, Russia) under the isocratic elution with the solvent mixture hexane/isopropanol/acetic acid (98.1:1.8:0.1, by volume) at a flow rate of $0.4 \mathrm{~mL} / \mathrm{min}$. Hydroperoxides were chromatographically pure and at least $98 \%$ optically pure, as judged by chiral phase HPLC [44].

\subsection{Bioinformatic Methods}

The NCBI database was used for the search of the CYP74-related genes. Primer construction and multiple sequence alignments were performed using the Vector NTI program (Invitrogen, USA). The BLAST analyses of the CYP74s were performed using the protein BLAST tool. The multiple alignments of selected CYP74 amino acid sequences and phylogenetic tree building were made with MEGA7 software [45]. Multiple alignment was performed using the Muscle method, the phylogenetic tree was built by means of the maximum likelihood method based on the Poisson correction model [46], and the bootstrap consensus tree was inferred from 1000 replicates [47]. The analysis involved 54 amino acid sequences.

\subsection{Expression and Purification of Recombinant Enzyme}

The target sequence was adapted for obtaining recombinant enzyme in Escherichia coli cells and synthesized in ZAO Evrogen (Russia). The resulting sequence was cloned into the pET-23a (Novagen, USA) vector using NdeI and XhoI endonucleases to yield the target recombinant protein with His-tagged C-terminus. The resulting construction was transformed into Escherichia coli host strain BL21(DE3)pLysS (Novagen, USA). The heterologous expression of recombinant protein was performed in the LB/M9 mixed medium (1:1, by volume) supplemented with antibiotics at $37^{\circ} \mathrm{C}$ until the cell culture reached an $\mathrm{OD}_{600}$ of 0.6-0.8. The expression of the recombinant gene in E. coli cells was induced by adding $0.5 \mathrm{mM}$ isopropyl- $\beta-D-1$-thiogalactopyranoside to the medium and the 5 -aminolevulinic acid $(100 \mathrm{mg} / \mathrm{L})$, which facilitates the heme formation. The His-tagged recombinant protein was purified by immobilized metal affinity chromatography (IMAC) using Bio-Scale Mini Profinity IMAC cartridge and BioLogic LP chromatographic system (Bio-Rad, USA). The relative purity of the recombinant protein was measured by SDS-PAGE and staining of the gel with Coomassie brilliant blue R-250. Protein concentration was estimated as described before [48].

\subsection{Kinetic Studies of Recombinant Enzyme}

Enzymatic activity of the purified recombinant enzyme was determined by monitoring the decrease of the signal at $234 \mathrm{~nm}$ in a PB $2201 \mathrm{~B}$ spectrophotometer (ZAO SOLAR, Belarus) with substrate concentrations ranging from 5 to $150 \mu \mathrm{M}$. The analyses were performed in $0.6 \mathrm{~mL}$ of Na phosphate buffer $(\mathrm{pH} 6.0-8.0)$ at $25^{\circ} \mathrm{C}$. The initial linear regions of the kinetic curves were used to calculate the rates. The molar extinction coefficient for 9and 13-hydroperoxides of linoleic acid at $234 \mathrm{~nm}$ is $25,000 \mathrm{M}^{-1} \mathrm{~cm}^{-1}$. Kinetic parameters were calculated by fitting the datasets to a one-site saturation model for simple ligand binding using the SigmaPlot 11 software (Systat Software Inc., USA). Five independent experiments were performed for each specified variant. 


\subsection{Incubations of Recombinant Enzyme with Substrates}

The recombinant enzyme $(10 \mu \mathrm{g})$ was incubated with $100 \mu \mathrm{g}$ of 9-HPOD, 9-HPOT, 13HPOD, 13-HPOT, 15-HPETE, or 15-HPEPE in Na phosphate buffer (100 mM, $10 \mathrm{~mL})$, pH 7.0, $4{ }^{\circ} \mathrm{C}$, for $15 \mathrm{~min}$. The reaction mixture was acidified to $\mathrm{pH} 6.0$, and the products were extracted with hexane/ethyl acetate (1:1, by volume) mixture, methylated with ethereal diazomethane and trimethylsilylated with pyridine/hexamethyldisilazane/trimethylchlorosilane (1:1:1, by volume) mixture at $23{ }^{\circ} \mathrm{C}$ for $30 \mathrm{~min}$. Then, the silylation reagents were evaporated in vacuo. The dry residue was dissolved in $100 \mu \mathrm{L}$ of hexane and subjected to GC-MS analyses. When specified, the products were reduced with $\mathrm{NaBH}_{4}$, then methylated and trimethylsilylated. Alternatively, the products of $\mathrm{NaBH}_{4}$ reduction were hydrogenated over $\mathrm{PtO}_{2}$, and then methylated and trimethylsilylated. Products (without or with the preliminary $\mathrm{NaBH}_{4}$ reduction) were analyzed as Me esters/TMS derivatives (Me/TMS) by GC-MS, as described previously [21].

\subsection{Methods of Instrumental Analyses}

The UV spectra of the reaction mixtures were scanned during the incubations of CYP440A18 with fatty acid hydroperoxides with Varian Cary 50 spectrophotometer. Alternatively, the UV spectra of products were recorded online during the HPLC separations using an SPD-M20A diode array detector (Shimadzu, Japan). Products (Me esters or $\mathrm{Me}$ /TMS derivatives) were analyzed by GC-MS as described previously [21]. GC-MS analyses were performed using a Shimadzu QP5050A mass spectrometer connected to a Shimadzu GC-17A gas chromatograph equipped with an MDN-5S (5\% phenyl 95\% methylpolysiloxane) fused capillary column (length, $30 \mathrm{~m}$; ID $0.25 \mathrm{~mm}$; film thickness, $0.25 \mu \mathrm{m})$. Helium at a flow rate of $30 \mathrm{~cm} / \mathrm{s}$ was used as the carrier gas. Injections were made in the split mode using an initial column temperature of $120^{\circ} \mathrm{C}$, injector temperature $230^{\circ} \mathrm{C}$. The column temperature was raised at $10^{\circ} \mathrm{C} / \mathrm{min}$ until it reached $240{ }^{\circ} \mathrm{C}$. Electron impact ionization $(70 \mathrm{eV})$ was used.

Supplementary Materials: The following are available online at https:/ / www.mdpi.com/article/10 $.3390 /$ ijms22094737/s1.

Author Contributions: Conceptualization, A.N.G.; methodology and validation, N.V.L.; formal analysis and investigation, E.O.S.; resources and data curation, L.S.M.; original draft preparation, review, and editing, A.N.G. and Y.Y.T.; supervision and project administration, Y.Y.T. All authors have read and agreed to the published version of the manuscript.

Funding: The authors are thankful for the financial support from the government assignment for FRC Kazan Scientific Center of RAS (mechanistic and phylogenetic studies). N.L. thanks the Russian Science Foundation (project no. 20-14-00338) for financial support (obtaining and purification of the CYP440A18 enzyme, kinetic studies). L.M. thanks the Russian Foundation of Basic Research (RFBR, project no. 20-34-70126) for financial support (study of reaction products of enzyme). E.S. thanks the RFBR (project no. 20-04-01069) for financial support (bioinformatic studies).

Institutional Review Board Statement: Not applicable.

Informed Consent Statement: Not applicable.

Data Availability Statement: Not applicable.

Conflicts of Interest: The authors declare no conflict of interest.

\section{References}

1. Zhang, Q.-L.; Zhang, G.-L.; Yuan, M.-L.; Dong, Z.-X.; Li, H.-W.; Guo, J.; Wang, F.; Deng, X.-Y.; Chen, J.-Y.; Lin, L.-B. A Phylogenomic Framework and Divergence History of Cephalochordata Amphioxus. Front. Physiol. 2018, 9. [CrossRef] [PubMed]

2. Cameron, C.B.; Garey, J.R.; Swalla, B.J. Evolution of the chordate body plan: New insights from phylogenetic analyses of deuterostome phyla. Proc. Natl. Acad. Sci. USA 2000, 97, 4469-4474. [CrossRef]

3. Graham, A. Evolution and Development: Rise of the Little Squirts. Curr. Biol. 2004, 14, R956-R958. [CrossRef] [PubMed]

4. Delsuc, F.; Brinkmann, H.; Chourrout, D.; Philippe, H. Tunicates and not cephalochordates are the closest living relatives of vertebrates. Nature 2006, 439, 965-968. [CrossRef] 
5. You, L.; Chi, J.; Huang, S.; Yu, T.; Huang, G.; Feng, Y.; Sang, X.; Gao, X.; Li, T.; Yue, Z.; et al. LanceletDB: An integrated genome database for lancelet, comparing domain types and combination in orthologues among lancelet and other species. Database 2019, 2019, 056. [CrossRef] [PubMed]

6. $\quad$ Putnam, N.H.; Butts, T.; Ferrier, D.E.K.; Furlong, R.F.; Hellsten, U.; Kawashima, T.; Robinson-Rechavi, M.; Shoguchi, E.; Terry, A.; $\mathrm{Yu}$, J.-K.; et al. The amphioxus genome and the evolution of the chordate karyotype. Nature 2008, 453, 1064-1071. [CrossRef] [PubMed]

7. Bi, C.; Lu, N.; Han, T.; Huang, Z.; Chen, J.-Y.; He, C.; Lu, Z. Whole-Genome Resequencing of Twenty Branchiostoma belcheri Individuals Provides a Brand-New Variant Dataset for Branchiostoma. BioMed Res. Int. 2020, 2020, 3697342. [CrossRef]

8. Gerwick, W.H.; Moghaddam, M.; Hamberg, M. Oxylipin metabolism in the red alga Gracilariopsis lemaneiformis: Mechanism of formation of vicinal dihydroxy fatty acids. Arch. Biochem. Biophys. 1991, 290, 436-444. [CrossRef]

9. Ortiz de Montellano, P.R.; Nelson, S.D. Rearrangement reactions catalyzed by cytochrome P450s. Arch. Biochem. Biophys. 2011, 507, 95-110. [CrossRef] [PubMed]

10. Poulos, T.L. Heme Enzyme Structure and Function. Chem. Rev. 2014, 114, 3919-3962. [CrossRef]

11. Nelson, D.R.; Goldstone, J.V.; Stegeman, J.J. The cytochrome P450 genesis locus: The origin and evolution of animal cytochrome P450s. Philos. Trans. R. Soc. B Biol. Sci. 2013, 368, 20120474. [CrossRef]

12. Grechkin, A. Recent developments in biochemistry of the plant lipoxygenase pathway. Prog. Lipid Res. 1998, 37, 317-352. [CrossRef]

13. Hughes, R.K.; De Domenico, S.; Santino, A. Plant Cytochrome CYP74 Family: Biochemical Features, Endocellular Localisation, Activation Mechanism in Plant Defence and Improvements for Industrial Applications. ChemBioChem 2009, 10, 1122-1133. [CrossRef] [PubMed]

14. Nelson, D.; Werck-Reichhart, D. A P450-centric view of plant evolution. Plant J. 2011, 66, 194-211. [CrossRef] [PubMed]

15. Lee, D.-S.; Nioche, P.; Hamberg, M.; Raman, C.S. Structural insights into the evolutionary paths of oxylipin biosynthesis enzymes. Nature 2008, 455, 363-370. [CrossRef]

16. Koeduka, T.; Ishizaki, K.; Mwenda, C.M.; Hori, K.; Sasaki-Sekimoto, Y.; Ohta, H.; Kohchi, T.; Matsui, K. Biochemical characterization of allene oxide synthases from the liverwort Marchantia polymorpha and green microalgae Klebsormidium flaccidum provides insight into the evolutionary divergence of the plant CYP74 family. Planta 2015, 242, 1175-1186. [CrossRef] [PubMed]

17. Toporkova, Y.Y.; Fatykhova, V.S.; Gogolev, Y.V.; Khairutdinov, B.I.; Mukhtarova, L.S.; Grechkin, A.N. Epoxyalcohol synthase of Ectocarpus siliculosus. First CYP74-related enzyme of oxylipin biosynthesis in brown algae. ACTA (BBA) Mol. Cell Biol. Lipids 2017, 1862, 167-175. [CrossRef]

18. Brash, A.R. Mechanistic aspects of CYP74 allene oxide synthases and related cytochrome P450 enzymes. Phytochemistry 2009, 70, 1522-1531. [CrossRef] [PubMed]

19. Grechkin, A.N. Hydroperoxide lyase and divinyl ether synthase. Prostaglandins Other Lipid. Mediat. 2002, 68-69, 457-470. [CrossRef]

20. Grechkin, A.N.; Hamberg, M. The "heterolytic hydroperoxide lyase" is an isomerase producing a short-lived fatty acid hemiacetal. Biochim. Biophys. Acta Mol. Cell Biol. Lipids 2004, 1636, 47-58. [CrossRef]

21. Grechkin, A.N.; Brühlmann, F.; Mukhtarova, L.S.; Gogolev, Y.V.; Hamberg, M. Hydroperoxide lyases (CYP74C and CYP74B) catalyze the homolytic isomerization of fatty acid hydroperoxides into hemiacetals. Acta Mol. Cell Biol. Lipids 2006, 1761, 1419-1428. [CrossRef] [PubMed]

22. Mukhtarova, L.S.; Brühlmann, F.; Hamberg, M.; Khairutdinov, B.I.; Grechkin, A.N. Plant hydroperoxide-cleaving enzymes (CYP74 family) function as hemiacetal synthases: Structural proof of hemiacetals by NMR spectroscopy. Biochim. Biophys. Acta Mol. Cell Biol. Lipids 2018, 1863, 1316-1322. [CrossRef] [PubMed]

23. Toporkova, Y.Y.; Gorina, S.S.; Mukhitova, F.K.; Hamberg, M.; Ilyina, T.M.; Mukhtarova, L.S.; Grechkin, A.N. Identification of CYP443D1 (CYP74 clan) of Nematostella vectensis as a first cnidarian epoxyalcohol synthase and insights into its catalytic mechanism. Acta Mol. Cell Biol. Lipids 2017, 1862, 1099-1109. [CrossRef] [PubMed]

24. Toporkova, Y.Y.; Smirnova, E.O.; Gorina, S.S.; Mukhtarova, L.S.; Grechkin, A.N. Detection of the first higher plant epoxyalcohol synthase: Molecular cloning and characterisation of the CYP74M2 enzyme of spikemoss Selaginella moellendorffii. Phytochemistry 2018, 156, 73-82. [CrossRef]

25. Toporkova, Y.Y.; Fatykhova, V.S.; Gorina, S.S.; Mukhtarova, L.S.; Grechkin, A.N. Epoxyalcohol Synthase RjEAS (CYP74A88) from the Japanese Buttercup (Ranunculus japonicus): Cloning and Characterization of Catalytic Properties. Biochemistry 2019, 84, 171-180. [CrossRef] [PubMed]

26. Gorina, S.S.; Toporkova, Y.Y.; Mukhtarova, L.S.; Grechkin, A.N. The CYP443C1 (CYP74 clan) Cytochrome of Sea Anemone Nematostella vectensis-the First Metazoan Enzyme Possessing Hydroperoxide Lyase/Epoxyalcohol Synthase Activity. Dokl. Biochem. Biophys. 2019, 486, 192-196. [CrossRef] [PubMed]

27. Toporkova, Y.Y.; Gorina, S.S.; Bessolitsyna, E.K.; Smirnova, E.O.; Fatykhova, V.S.; Brühlmann, F.; Ilyina, T.M.; Mukhtarova, L.S.; Grechkin, A.N. Double function hydroperoxide lyases/epoxyalcohol synthases (CYP74C) of higher plants: Identification and conversion into allene oxide synthases by site-directed mutagenesis. Acta Mol. Cell Biol. Lipids 2018, 1863, 369-378. [CrossRef]

28. Gorina, S.S.; Mukhitova, F.K.; Ilyina, T.M.; Toporkova, Y.Y.; Grechkin, A.N. Detection of unprecedented allene oxide synthase member of CYP74B subfamily: CYP74B33 of carrot (Daucus carota). ACTA Mol. Cell Biol. Lipids 2019, 1864, 1580-1590. [CrossRef] 
29. Toporkova, Y.Y.; Askarova, E.K.; Gorina, S.S.; Ogorodnikova, A.V.; Mukhtarova, L.S.; Grechkin, A.N. Epoxyalcohol synthase activity of the CYP74B enzymes of higher plants. ACTA Mol. Cell Biol. Lipids 2020, 1865, 158743. [CrossRef] [PubMed]

30. Hamberg, M. Regio- and stereochemical analysis of trihydroxyoctadecenoic acids derived from linoleic acid 9- and 13hydroperoxides. Lipids 1991, 26, 407-415. [CrossRef] [PubMed]

31. Grechkin, A.; Kuramshin, R.; Safonova, E.; Latypov, S.; Ilyasov, A. Formation of ketols from linolenic acid 13-hydroperoxide via allene oxide. Evidence for two distinct mechanisms of allene oxide hydrolysis. Acta Lipids Lipid Metab. 1991, 1086, 317-325. [CrossRef]

32. Hamberg, M. Mechanism of corn hydroperoxide isomerase: Detection of 12,13(S)-oxido-9(Z),11-octadecadienoic acid. Acta Lipids Lipid Metab. 1987, 920, 76-84. [CrossRef]

33. Grechkin, A.N.; Mukhtarova, L.S.; Latypova, L.R.; Gogolev, Y.; Toporkova, Y.Y.; Hamberg, M. Tomato CYP74C3 is a Multifunctional Enzyme not only Synthesizing Allene Oxide but also Catalyzing its Hydrolysis and Cyclization. ChemBioChem 2008, 9 , 2498-2505. [CrossRef] [PubMed]

34. Hamberg, M. A pathway for biosynthesis of divinyl ether fatty acids in green leaves. Lipids 1998, 33, 1061-1071. [CrossRef]

35. Ziegler, J.; Wasternack, C.; Hamberg, M. On the specificity of allene oxide cyclase. Lipids 1999, 34, 1005-1015. [CrossRef]

36. Grechkin, A.N. Cyclization of natural allene oxide fatty acids. The anchimeric assistance of $\beta, \gamma$-double bond beside the oxirane and the reaction mechanism. ACTA Lipids Lipid Metab. 1994, 1213, 199-206. [CrossRef]

37. González-Pérez, A.B.; Grechkin, A.; De Lera, A.R. Rearrangement of vinyl allene oxide geometric isomers to cyclopentenones. Further computational insights with biologically relevant model systems. Org. Biomol. Chem. 2017, 15, 2846-2855. [CrossRef]

38. Koljak, R.; Boutaud, O.; Shieh, B.-H.; Samel, N.; Brash, A.R. Identification of a Naturally Occurring Peroxidase-Lipoxygenase Fusion Protein. Science 1997, 277, 1994-1996. [CrossRef] [PubMed]

39. Varvas, K.; Järving, I.; Koljak, R.; Valmsen, K.; Brash, A.R.; Samel, N. Evidence of a Cyclooxygenase-related Prostaglandin Synthesis in Coral. J. Biol. Chem. 1999, 274, 9923-9929. [CrossRef] [PubMed]

40. Löhelaid, H.; Teder, T.; Tõldsepp, K.; Ekins, M.; Samel, N. Up-Regulated Expression of AOS-LOXa and Increased Eicosanoid Synthesis in Response to Coral Wounding. PLoS ONE 2014, 9, e89215. [CrossRef] [PubMed]

41. Gao, B.; Boeglin, W.E.; Zheng, Y.; Schneider, C.; Brash, A.R. Evidence for an Ionic Intermediate in the Transformation of Fatty Acid Hydroperoxide by a Catalase-related Allene Oxide Synthase from the Cyanobacterium Acaryochloris marina. J. Biol. Chem. 2009, 284, 22087-22098. [CrossRef] [PubMed]

42. Mashhadi, Z.; Newcomer, M.E.; Brash, A.R. The Thr-His Connection on the Distal Heme of Catalase-Related Hemoproteins: A Hallmark of Reaction with Fatty Acid Hydroperoxides. ChemBioChem 2016, 17, 2000-2006. [CrossRef] [PubMed]

43. Wilson, R.A.; Gardner, H.W.; Keller, N.P. Cultivar-Dependent Expression of a Maize Lipoxygenase Responsive to Seed Infesting Fungi. Mol. Plant. Microbe Interact. 2001, 14, 980-987. [CrossRef]

44. Chechetkin, I.R.; Osipova, E.V.; Tarasova, N.B.; Mukhitova, F.K.; Hamberg, M.; Gogolev, Y.V.; Grechkin, A.N. Specificity of oxidation of linoleic acid homologs by plant lipoxygenases. Biochemistry 2009, 74, 855-861. [CrossRef] [PubMed]

45. Kumar, S.; Stecher, G.; Tamura, K. MEGA7: Molecular Evolutionary Genetics Analysis Version 7.0 for Bigger Datasets. Mol. Biol. Evol. 2016, 33, 1870-1874. [CrossRef] [PubMed]

46. Zuckerkandl, E.; Pauling, L. Evolutionary divergence and convergence in proteins. In Evolving Genes and Proteins; Bryson, V., Vogel, H.J., Eds.; Academic Press: New York, NY, USA, 1965; pp. 97-166.

47. Felsenstein, J. Confidence limits on phylogenies: An approach using the bootstrap. Evolution 1985, 39, 783-791. [CrossRef]

48. Schenkman, J.B.; Jansson, I.; Ian, P.R.; Elizabeth, S.A. Spectral Analyses of Cytochromes P450. In Cytochrome P450 Protocols; Humana Press: Totowa, NJ, USA, 2006; Volume 320, pp. 11-18. [CrossRef] 